\title{
Linking embryonic temperature with adult reproductive investment in Atlantic salmon Salmo salar
}

\author{
Bror Jonsson $^{1, *}$, Nina Jonsson ${ }^{1}$, Anders G. Finstad ${ }^{2}$ \\ ${ }^{1}$ Norwegian Institute for Nature Research, Gaustadalléen 21, 0349 Oslo, Norway \\ ${ }^{2}$ Norwegian Institute for Nature Research, PO Box 5685 Sluppen, 7485 Trondheim, Norway
}

\begin{abstract}
The expression of fitness-related traits, such as egg and gonad size, often varies among habitats and exhibits clinal variation along climatic and latitudinal gradients. However, the mechanisms allowing such variations are obscure and have been ascribed to both phenotypic plasticity and genetic adaptation. We experimentally tested whether variation in egg and gonad size of a poikilotherm vertebrate is influenced by the temperature individuals experienced during embryogenesis, possibly as an epigenetic effect. Atlantic salmon Salmo salar eggs were incubated under 3 embryonic thermal regimes: cold, mixed and warm treatments. The cold group received ambient river water (mean $\pm \mathrm{SD}: 2.6 \pm 0.4^{\circ} \mathrm{C}$ ) and the warm group received water at $4.6^{\circ} \mathrm{C}$ above ambient temperature, the expected temperature in the river towards the end of this century, from fertilization until exogenous feeding commenced. The mixed group received ambient river water until hatching, whereupon the larvae received heated water until exogenous feeding commenced. When exogenous feeding was initiated, all fish were reared under identical, natural thermal conditions. At adulthood, fish that developed from warm-incubated eggs were largest, had the highest mass-length relationship and developed larger eggs and higher gonad mass relative to their own body size. There was no similar effect of thermal environment during larval development. The treatment did not affect age of maturity or fecundity. Thus, thermal conditions during embryogenesis affected the expression of adult life-history traits, a mechanism by which fish may rapidly change the size of their propagules to the anticipated thermal offspring environment. This is a novel result explaining variation in these core life-history traits.
\end{abstract}

KEY WORDS: Egg size $\cdot$ Epigenetics $\cdot$ Fecundity $\cdot$ Gonad mass $\cdot$ Phenotypic plasticity $\cdot$ Salmo salar . Thermal regime

Resale or republication not permitted without written consent of the publisher

\section{INTRODUCTION}

Early thermal environments can influence later performance of animals. For almost a century, research has revealed how embryonic environments can influence meristic and morphological characters (e.g. Tåning 1952). More recent studies have shown that thermal conditions early in life can also influence subsequent growth, energy stores and sex determination (Braña \& Ji 2000, Ospina-Álvarez \& Piferrer 2008, Potter et al. 2011). Thus, the early environment can have long-lasting effects on the competitive abilities, reproductive rate and other fitness-related traits of organisms.

The thermal environment is an important factor affecting animal performance, for instance growth and body size (Atkinson \& Sibly 1997, Forster et al. 2012). Organisms tend to be bigger in colder climates, with effects on associated variables such as the mass-length relationships and age at maturity (Jonsson et al. 2013). Despite increasing interest in temperature mediation of organismal functioning 
across life-history stages, enforced by research on effects of global warming on ecological systems, little is known about how thermal conditions during the embryonic stage affect core adult life-history characters later in life.

Phenotypes emerge from complex interactions between genes and environments (Gilbert \& Epel 2008), and developmental effects can be caused by conditions experienced during embryogenesis. Favourable temperatures during egg incubation can increase developmental rates and give some individuals head starts relative to conspecifics raised under less favourable conditions (Descamps et al. 2008, Warner et al. 2010). During the last $70 \mathrm{yr}$, numerous studies have investigated environmental effects on egg size and fecundity (Lack 1947, Einum \& Fleming 2002, Bownds et al. 2010). Theory predicts that mothers should alter the size and number of their offspring according to local environmental conditions to maximize their long-term fitness (Svärdson 1949, Smith \& Fretwell 1974, Brockleman 1975). Latitudinal gradient studies have shown among-population variation in egg size and fecundity, and variation does occur with change in temperature (Fleming \& Gross 1990, Martin 2008, Stillwell \& Fox 2009). However, the mechanistic and functional basis for this is not clear (Fischer \& Karl 2010), as observational studies can be confounded by factors other than temperature, such as feeding opportunity and growth rate. Furthermore, field studies do not distinguish evolutionary responses to selection from adaptive phenotypic plasticity as causal mechanisms (Braun et al. 2013). In addition, experimental studies testing effects of early growth on egg size have reported divergent results for closely related species (Jonsson et al. 1996, Quinn et al. 2011), with no explanation as to why.

Phenotypically plastic adaptations in breeding ecology may occur in long-distance migratory species, such as Atlantic salmon Salmo salar-an anadromous species with a complex life cycle. It breeds in rivers where the young grow for at least $1 \mathrm{yr}$ until smolting pre-adapts them for ocean life. Typically, the fish feed for at least $1 \mathrm{yr}$ in the North Atlantic Ocean, often more than $1000 \mathrm{~km}$ from the nursery river, before attaining maturity and returning to fresh water for breeding, usually in the river they left as young (Jonsson \& Jonsson 2011). In this species, juvenile and adult environments are very dissimilar, and the adults cannot experience the conditions in the breeding area when they attain maturity and start developing their propagules. Relatively large gametes are more favourable in warm than in colder environments (Beacham \& Murray 1985, Blancken- horn \& Hellriegel 2002), and a phenotypically plastic mechanism adjusting gamete size to expected thermal conditions in the breeding and nursery area would be beneficial. Functional links between embryonic conditions and the development of fitness-related characters may be selectively favourable, not the least for ectothermic animals where thermal conditions largely influence offspring success (Weber et al. 2012). At present, little is known about whether such an adaptation exists.

Here we experimentally tested whether egg and gonadal size of a poikilotherm vertebrate is influenced by the temperature the individuals experienced during their own embryogenesis. We also investigated whether water temperature during embryogenesis and larval development affected their age and size at maturity, mass-length relationship, gonad mass, egg size and fecundity. As our study organism we used Atlantic salmon, an economically important teleost fish in rivers of the North Atlantic basin, and hypothesized that increased embryonic and larval temperatures would stimulate growth, resulting in larger adults with higher body mass relative to length, decreased age at maturity, increased egg and gonad sizes and reduced fecundity. Embryos and larvae were incubated at 2 different temperatures until the commencement of external feeding. They were then reared at a common temperature in a hatchery for $1 \mathrm{yr}$, transferred to seawater tanks and reared for another 2 yr until most of them attained sexual maturity. To our knowledge, no previous study has experimentally tested the effects of elevated temperature during egg and larval development on these adult life-history characters.

\section{MATERIALS AND METHODS}

The experiment was conducted at the NINA Research Station, Ims, in southwestern Norway $\left(59^{\circ} \mathrm{N}, 6^{\circ} \mathrm{E}\right)$ from November 2010 to December 2013. The fish used in the experiment were offspring of 1-sea-winter adult Atlantic salmon $(55-60 \mathrm{~cm}$ in length) collected when returning from the sea to the River Imsa ( $59^{\circ} \mathrm{N}, 6^{\circ} \mathrm{E}$ ) (cf. Jonsson et al. 2003). Eggs were collected from 24 females and fertilized by sperm from 2 males for each female (29 October 2010). Each half-sib-group was split into 3 evenly sized groups for use in the 3 different embryonic thermal treatments, hereafter termed cold, mixed and warm thermal treatments. The cold and warm group received either natural river water (ambient temperature, mean $\pm \mathrm{SD}: 2.6 \pm 0.4^{\circ} \mathrm{C}$ ) or heated river 
water $\left(7.2 \pm 0.6^{\circ} \mathrm{C}\right)$ from fertilization to exogenous feeding, respectively (Fig. 1). At the time of egg hatching in the cold temperature treatment (9 March 2011), half of these fish (mixed thermal treatment) were transferred to heated water and reared in heated water until the natural water temperature approached that of the heated ones, and the heating system was turned off and the cold and mixed group were at the same temperature until exogenous feeding (Fig. 1). Slightly higher egg mortality occurred in the warm-water- $(27 \%)$ than in the cold-watertreated group $(19 \%)$.

Half-sib groups were maintained separately until the onset of exogenous feeding ( $24 \times 3$ groups), after which fish from the same thermal treatment groups were combined $(3 \times 2$ groups). From the onset of exogenous feeding (April/May 2011) until smolting (April 2012), the fish from the different thermal treatments were reared at ambient river temperatures, ranging from 1.2 to $20.7^{\circ} \mathrm{C}$, and fed to satiation with commercial pellets for salmon (www.ewos.com). The smolts were individually tagged with passive integrated transponder tags after anaesthetization with benzocaine on 19 April 2012, so that the growth trajectory of each individual could be followed and adult life-history traits correlated with these. The fish were gradually adapted to seawater from 29 April to 3 May 2012. The fish were then reared in separate seawater rearing tanks with 2 replicate tanks per treatment and fed to satiation on pellets for marine

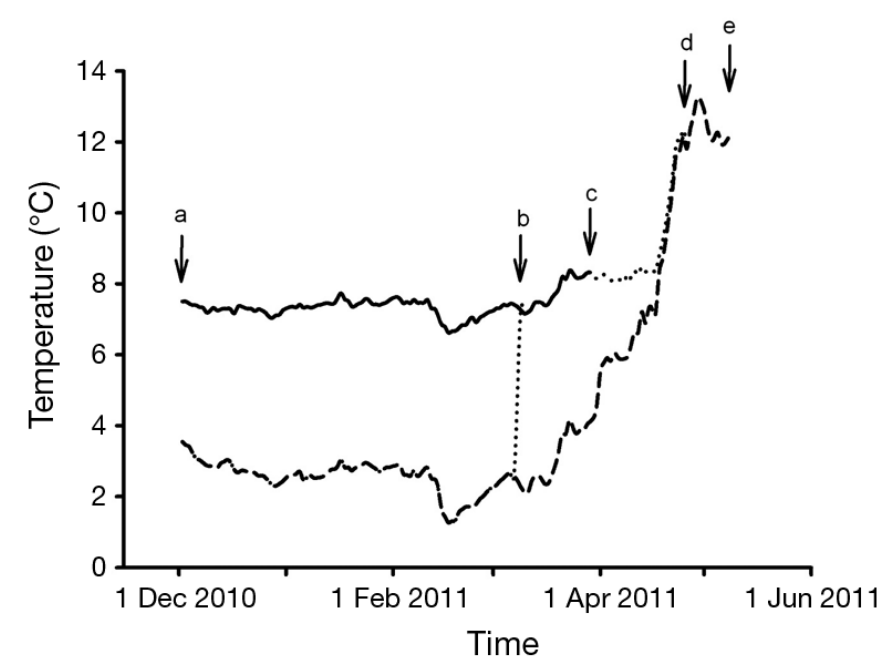

Fig. 1. Water temperature during embryonic and larval development of Atlantic salmon Salmo salar in heated (solid line), mixed (dotted line) and natural (dashed line) incubation temperature treatments. Arrows indicate date of (a) fertilization, (b) transfer of the mixed treatment from natural to heated temperatures, and start of exogenous feeding for (c) heated, (d) mixed and (e) natural treatment fish salmon rearing (Ewos opal). One of the cold-water replicates had to be terminated before the end of the experiment (9 May 2012) due to technical issues with the water supply. We did not find any significant difference between the replicated groups (tank effects) that may have altered the statistical inference due to the lack of replication of the cold-water-treated group (see last paragraph of 'Materials and methods'). The water used for rearing was pumped from $30 \mathrm{~m}$ depth in the bay outside of Ims. Salinity was measured once a week with an areometer (Sterner Fish Tech) and mean $( \pm \mathrm{SD}$ ) salinity was $31.9 \pm 1.0$ psu (range: 29.5-35.5 psu). Seawater temperatures, which were registered every second hour by water temperature data loggers (HOBO Pro v2), ranged from 3.7 to $16.5^{\circ} \mathrm{C}$ during rearing.

Natural tip length $(L, \mathrm{~mm})$ and mass $(W, \mathrm{~g})$ of all fish were measured at the seawater transfer, again in November 2012 (Age-1) and at the termination of the experiment in November/December 2013 (Age-2) when females ovulated. The females were checked for ovulation status once a week from early November to 16 December. At ovulation, the females were sacrificed with an overdose of benzocaine. Males were sacrificed on 12 and 13 November when the first females had ovulated. We measured somatic and gonad mass (excluding female ovarian fluid) (g), fecundity as the number of ovulated eggs in each female and mean individual egg mass $(0.1 \mathrm{mg})$ by weighing a subset of 10 eggs, selected at random from each female. There was no difference in time of ovulation among treatment groups.

Growth $(G)$ in length during defined periods of time $\left(t_{2}-t_{1}\right)$ was calculated as: $G=\left(\log _{\mathrm{e}} L_{2}-\right.$ $\left.\log _{\mathrm{e}} L_{1}\right) /\left(t_{2}-t_{1}\right)$, where $L_{1}$ and $L_{2}$ are the respective lengths in $\mathrm{mm}$ at time $t_{1}$ and $t_{2}$, expressed in days. At hatching, the length of the salmon was set at $20 \mathrm{~mm}$, which is the typical hatching length in this river (Jonsson et al. 2005). However, the embryo size may vary with the size of the mother and incubation temperature (Kamler 1992). $G_{1}$ covers the period from hatch until age 1 and $G_{2}$ is from age 1 until age 2. The relationship between mass and length $(C$, condition factor) was evaluated using Fulton's formula $C=100\left(W / L^{3}\right)$, where $W(\mathrm{~g})$ is body mass. We used Fulton's condition factor, as it has been shown to be closely related to energy density for both sexes of the River Imsa Atlantic salmon (Jonsson \& Jonsson 2003).

In order to test for effects of embryonic thermal conditions on adult length or condition factor, we employed an ANOVA with treatments as factors and individual adult length or condition factor as the 
response variable. To test for effects of treatment on growth rates from Age-1 to Age-2 $(G)$, a linear model analysis was used; embryonic thermal treatment was entered as a factor $(T)$, and length $(L)$ and condition factor $(C)$ at the start of the growth period were entered as covariates to correct for energetic and size effects on growth. We initially started with a full model including all covariates, including length and condition factor interactions:

$$
G=\beta_{0}+\beta_{1} T+\beta_{2} L+\beta_{3} C_{+}+\beta_{4} L C+\varepsilon
$$

where $\beta_{\mathrm{n}}$ represent estimated coefficients. We did not find any significant influence of replicate (tank effect; details below).

Effects of thermal treatment on egg size, fecundity and gonad mass were run as a set of linear models; embryonic thermal treatment was entered as a factor, and growth in the first and second year $\left(G_{1}\right.$ and $\left.G_{2}\right)$, and length and condition factor at maturity were entered as covariates. We initially started with a full model including all covariates and also including length and condition factor interactions:

$$
\begin{aligned}
Y= & \beta_{0}+\beta_{1} T+\beta_{2} L+\beta_{3} C+ \\
& \beta_{4} G_{1}+\beta_{5} G_{2}+\beta_{6} L C+\varepsilon
\end{aligned}
$$

where $Y$ represents either egg size, fecundity, or male or female gonad mass and $\beta_{n}$ represent estimated coefficients. As in the previous analyses, we did not find any significant influence of replicate (tank effect; see details below)

All models were run separately for each sex. Initial analyses did not detect any variation in slope between covariates and thermal treatment (i.e. treatment $\times$ covariate interactions) and these were left out of the full model. We selected the most parsimonious model by means of multi-model comparisons using the small sample unbiased Akaike information criterion (AICc) as the selection criterion (Johnson \& Omland 2004). When selecting among candidate models, we chose the simplest model with a $\triangle \mathrm{AICC}$ (difference between candidate model and best model) $<2$. However, the temperature effect was retained in the selected model even when this criterion was not followed. Model selection tables are given as Tables S1 \& S2 in the Supplement at www. int-res.com/articles/suppl/m515p217_supp.pdf. All analyses were performed with $\mathrm{R}$ software version 2.9.2 (R Development Core Team 2009).

We tested for the effect of replication (tank effect) using data from the mixed and warm embryonic temperature treatment. Here, replicate (tank) was entered as a factor into the full model (Eqs. 1 \& 2). There were no significant effects of replicate, and all model selections excluded replicate ( $\triangle \mathrm{AICc}$ support for models including replicate $<0.6$ ). In addition, we entered replicate as a factor into the final selected model without finding any significant effect $(\triangle \mathrm{AICC}$ support for model including replicate $<0.27$ ).

\section{RESULTS}

Juvenile growth was faster in fish incubated in warm water, and smolt length (mean \pm SD) was longer in these fish $(158 \pm 11.3 \mathrm{~mm})$ than in the mixed $(151 \pm$ $10.9 \mathrm{~mm}$ ) and the cold-water incubated fish (148 \pm $9.6 \mathrm{~mm})$. This difference in length was significant (ANOVA, $F_{2,448}=28.7, \mathrm{p}<0.001$ ). The fish were also checked for sexual maturation in the autumn of 2012 (at Age-1) and 2013 (Age-2). In total, 11.2\% males attained maturity at Age-1 and 87.9\% at Age-2. In females, no fish attained maturity at Age-1, and 74.5\% attained maturity at Age-2. There was no significant difference in the proportion of mature females among treatments $\left(\chi_{2}^{2}=5.00, \mathrm{p}=0.08\right)$ at Age-2 or males at Age-1 $\left(\chi_{2}^{2}=1.76, \mathrm{p}=0.42\right)$ or Age- $2\left(\chi_{2}^{2}=0.006, \mathrm{p}=\right.$ $0.997)$. In the further analyses, we used males and females maturing at Age-2.

Adult length (mean \pm SD) differed between embryonic and larval thermal treatments (cold $=419 \pm$ $39.8 \mathrm{~mm}, \mathrm{n}=71$; mixed $=441 \pm 42.8 \mathrm{~mm}, \mathrm{n}=149$; warm $=459 \pm 51.5 \mathrm{~mm}, \mathrm{n}=148 ;$ ANOVA, $F_{2,365}=$ 18.76, p < 0.001; Tukey's multiple comparison test, all $\mathrm{p}<0.003$ ), but not between sexes (males $=445 \mathrm{~mm}$, females $443 \mathrm{~mm}, t_{366}=0.4, \mathrm{p}=0.69$ ). There was also a treatment effect on condition factor $($ cold $=0.97 \pm$ 0.075, mixed $=1.01 \pm 0.072$, warm $=1.02 \pm 0.080$; ANOVA, $\left.F_{2,364}=11.12, \mathrm{p}<0.001\right)$. Condition factor differed between cold and mixed, and between cold and warm treatments (Tukey's multiple comparison test, all $\mathrm{p}<0.003$ ), but not between mixed and warm treatments (Tukey's multiple comparison test, $\mathrm{p}=$ 0.217). This indicates that the effect on the masslength relationship occurred at the larval stage. Condition factor did not differ significantly between sexes (males: $1.01 \pm 0.067$, females: $1.00 \pm 0.087$, $\left.t_{365}=1.81, \mathrm{p}=0.07\right)$. There was no effect of treatment on growth rates during the year prior to maturation (Table 1). Accordingly, size must have differed between treatments during the juvenile growth period in fresh water.

Mean mass of the individual eggs was affected by embryonic thermal conditions, even after adjusting for adult length and condition factor (Fig. 2A, Table S1). Fish from the warm treatment group had higher egg mass than the cold and mixed groups; 
Table 1. Selected models for female and male Atlantic salmon Salmo salar growth rates from November 2012 to termination of the experiment in November/December 2013 against natural tip length $(L, \mathrm{~mm})$, condition factor $(C)$ and incubation temperature $(T)$ as factors; natural water during embryonic and larval development (intercept); natural water during embryogenesis and heated water during larval development $\left(T_{\text {mix }}\right)$; and heated water during embryonic and larval development $\left(T_{\text {warm }}\right)$. The interaction between total length and condition factor $(L \times C)$ was excluded from the model for females $(\triangle \mathrm{AIC}$ between selected model and next best model $<1.41$ ). Model statistics for females: $F_{4,172}=32.78$, $\mathrm{r}^{2}=0.41, \mathrm{p}<0.001 ;$ males: $\left.F_{5,166}=41.97, \mathrm{r}^{2}=0.55, \mathrm{p}<0.001\right)$

\begin{tabular}{|llrrr|}
\hline & & Parameter $\pm \mathrm{SE}$ & \multicolumn{1}{c|}{$t$} & $\mathrm{p}$ \\
\hline Female & Intercept & $-3.82 \pm 0.55$ & -6.93 & $<0.001$ \\
& $L$ & $0.01 \pm 0.01$ & 9.24 & $<0.001$ \\
& $C$ & $0.63 \pm 0.17$ & 3.70 & $<0.001$ \\
& $T_{\text {mix }}$ & $-0.13 \pm 0.10$ & -1.27 & 0.206 \\
& $T_{\text {warm }}$ & $0.11 \pm 0.11$ & 1.04 & 0.300 \\
Male & Intercept & $-10.66 \pm 1.38$ & -7.74 & $<0.001$ \\
& $L$ & $0.04 \pm 0.01$ & 7.55 & $<0.001$ \\
& $C$ & $4.37 \pm 0.90$ & 4.84 & $<0.001$ \\
& $T_{\text {mix }}$ & $-0.19 \pm 0.11$ & -1.73 & 0.086 \\
& $T_{\text {warm }}$ & $-0.03 \pm 0.11$ & -0.27 & 0.791 \\
& $L \times C$ & $-0.02 \pm 0.01$ & -4.18 & $<0.001$ \\
\hline
\end{tabular}

however, there was limited support for an effect of rearing temperature during larval development (Table 2). Furthermore, support was only limited for effects of juvenile growth rate during the first or second year on mean egg mass, or for interactions between adult length and condition factor (Table S2).

Female gonad mass increased with adult length and was affected by embryonic temperature conditions (Fig. 2B, Table S2). Specifically, ovary mass was greater in the warm group than in the cold and mixed temperature groups (Table 2), but there was a comparable smaller effect of rearing temperature during the larval phase (Fig. 2B). Support was limited for juvenile growth rate during the first or second year or the interactions between adult length and condition factor on female gonad mass (Table S2).

Fecundity increased with length $(L, \mathrm{~mm})$ at maturity in female Atlantic salmon (linear regression; Fecundity $=-4151.7( \pm 347.5 \mathrm{SE})+14.06( \pm 0.78 \mathrm{SE})$ $\left.L ; \mathrm{r}^{2}=0.65, F_{1,172}=323.6, \mathrm{p}<0.001\right)$. There was no treatment effect on fecundity, nor was fecundity affected by juvenile growth rate during the first or second year $(\triangle \mathrm{AIC}$ between selected model and next best model: 0.13).

Male gonad mass increased with body length and was larger in the warm than in the mixed and cold thermal treatment groups. There was no difference between the cold and mixed treatment groups (Fig. 2C, Table 2). Also, male gonad mass decreased
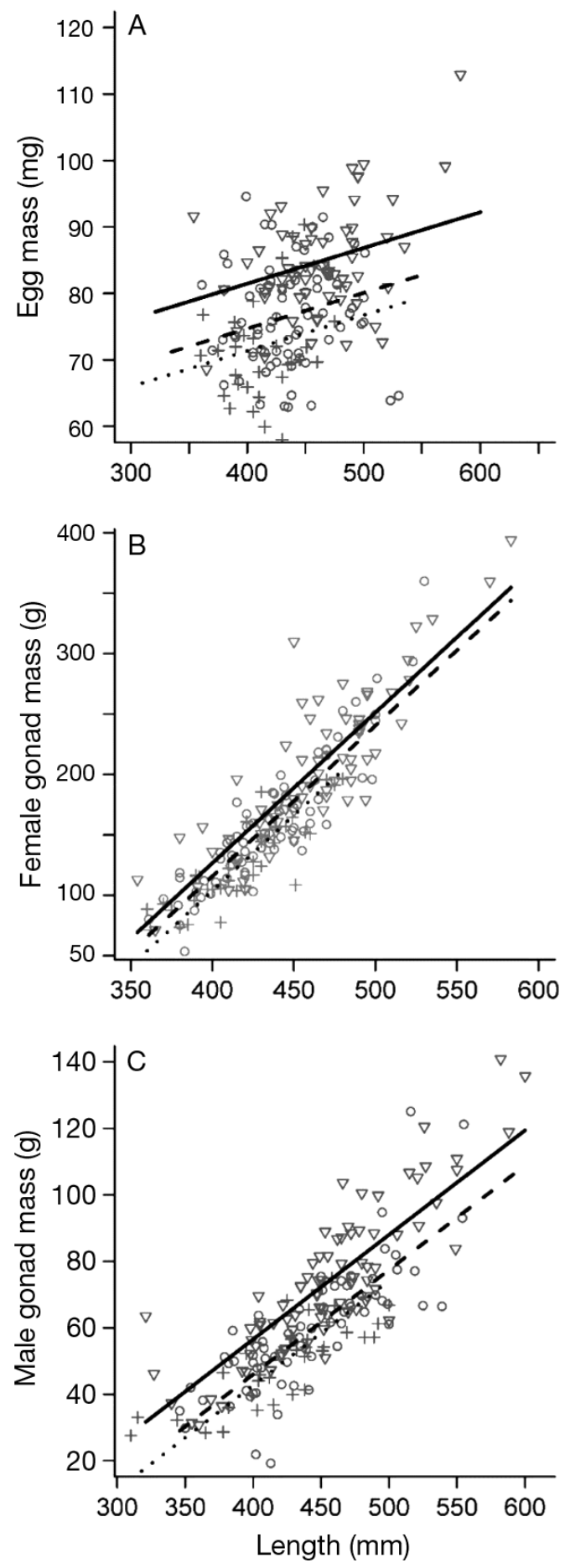

Fig. 2. Mean mass of (A) single eggs, (B) female gonads and (C) male gonads over total length $(\mathrm{mm})$ for adult Atlantic salmon Salmo salar incubated in natural water during embryonic and larval development (+, dotted lines), natural water during embryogenesis and heated water during larval development $(\mathrm{O}$, dashed lines), and heated water during embryonic and larval development $(\Delta$, solid lines). Lines are predictions from the best-fit model with regression parameters given in Table 2, standardized with mean condition factor across groups 
Table 2. Selected models for mean mass of Atlantic salmon Salmo salar single eggs, female gonad mass and male gonad mass against natural tip length $(L, \mathrm{~mm})$, condition factor $(C)$ and incubation temperature $(T)$ as factors; natural water during embryonic and larval developments (intercept); natural water temperature during the embryogenesis; heated water during larval development $\left(T_{\text {mix }}\right)$; and heated water during embryonic and larval development ( $\left.T_{\text {warm }}\right)$. Juvenile growth during the first $\left(G_{1}\right)$ and second $\left(G_{2}\right)$ year were also included in the model for male gonad mass. Model statistics for eggs: $F_{4,165}=24.09, \mathrm{r}^{2}=0.35, \mathrm{p}<0.001$; female gonad: $F_{4,173}=200.80, \mathrm{r}^{2}=0.81, \mathrm{p}<0.001 ;$ male gonad: $F_{3,176}=$ $106.90, \mathrm{r}^{2}=0.75, \mathrm{p}<0.001$

\begin{tabular}{|llcrr|}
\hline & & Parameter $\pm \mathrm{SE}$ & $t$ & $\mathrm{p}$ \\
\hline Eggs & Intercept & $26.70 \pm 9.36$ & 2.85 & $<0.001$ \\
& $L$ & $0.06 \pm 0.01$ & 3.90 & $<0.001$ \\
& $C$ & $23.05 \pm 6.87$ & 3.36 & $<0.001$ \\
& $T_{\text {mix }}$ & $2.10 \pm 1.62$ & 1.29 & 0.198 \\
& $T_{\text {warm }}$ & $8.24 \pm 1.79$ & 4.58 & $<0.001$ \\
Female & Intercept & $-465.89 \pm 32.46$ & -14.34 & $<0.001$ \\
gonad & $L$ & $1.25 \pm 0.05$ & 24.25 & $<0.001$ \\
& $C$ & $71.04 \pm 23.83$ & 2.98 & 0.003 \\
& $T_{\text {mix }}$ & $8.25 \pm 5.57$ & 2.98 & 0.141 \\
& $T_{\text {warm }}$ & $17.76 \pm 6.13$ & 2.89 & 0.004 \\
Male & Intercept & $278.52 \pm 144.01$ & 1.93 & $<0.001$ \\
gonad & $L$ & $0.35 \pm 0.02$ & 16.12 & $<0.001$ \\
& $T_{\text {mix }}$ & $4.59 \pm 2.37$ & 1.93 & 0.161 \\
& $T_{\text {warm }}$ & $13.01 \pm 2.35$ & 5.52 & $<0.001$ \\
& $G_{1}$ & $-72.67 \pm 29.80$ & -2.44 & 0.016 \\
& $G_{2}$ & $-30.70 \pm 11.27$ & -2.73 & 0.007 \\
\hline
\end{tabular}

with juvenile growth rate during both the first and second year (Fig. 2C, Tables 2 \& S2). Thus, warm water during embryogenesis increased the mass of the testes, whereas fast juvenile growth decreased the allocation of energy to the development of the testes. There was limited support for an interaction effect between adult length and condition factor (Table S2).

\section{DISCUSSION}

The temperature used in the experiment was similar to that expected to be reached in southern Norway towards the end of this century (Engen-Skaugen et al. 2007, IPCC 2013), but the increase occurred within 1 generation and not gradually over decades as it does in nature. Thus, it is possible that the observed changes in reproductive investment may have been influenced by the sudden exposure to the high temperatures early in life. On the other hand, the temperature used is similar to or lower than what Atlantic salmon embryos presently encounter in central and southern Europe; it is also lower than that typically used in commercial farming of Atlantic salmon. Furthermore, the optimum temperature range over which the highest percentage of embryos hatch is between 4 and $7^{\circ} \mathrm{C}$ (Humpesch 1985), indicating that the experimental temperature is within the range to which embryos of this species are adapted.

Our results indicate that adult salmon, when subjected to warm temperatures during their egg and larval stages, had higher juvenile growth rates and larger body sizes than adults that experienced ambient temperature conditions early in life. Finstad \& Jonsson (2012) showed that contrary to larval development, warm water during embryogenesis stimulated juvenile growth of salmon. To our knowledge, no study other than ours has demonstrated that thermal conditions experienced by embryos before hatching affect their adult body size. However, Ewert \& Nelson (1991) reported for turtles, in which adult females are larger than adult males, that high egg incubation temperature produces females (= large) and cooler temperatures produce males (= small).

Not only were adult body size and juvenile growth affected by embryonic conditions, but so were egg and ovarian mass. We found that mean egg mass was largest for females which were kept in warm water during embryogenesis. The similar egg and gonad masses of the cold and mixed groups indicates that warming during the larval stage had little or no effect on egg size variation. We found no significant tank effect, and the results on egg size show a similar tendency to that observed in studies of migratory salmonids (Fleming \& Gross 1990, Jonsson \& Jonsson 1999, Crossin et al. 2004). Furthermore, in a recent study, Braun et al. (2013) correlated stream temperature and egg size in a number of wild sockeye salmon Oncorhynchus nerka populations from the same latitude that migrated the same distance from the sea. The authors found that females in relatively warm streams produced larger eggs for their size than those from colder streams. Theoretically, offspring produced from large eggs are expected to have higher survival in warm environments than those from small eggs. The maintenance costs of developing larvae increase with temperature (Hamor \& Garside 1977), the conversion efficiency from yolk to body tissue decreases with increasing temperature (Murray \& McPhail 1988), small eggs are more susceptible to low dissolved oxygen level in the water than large eggs, and the oxygen content in the water decreases with temperature (Einum et al. 2002). Thus, females that spawn in warmer streams may maximize fitness by producing larger eggs than equal sized females from cooler streams (cf. Braun et al. 2013). 
Such a phenotypic response to embryonic temperature may be advantageous for fish colonizing rivers where offspring born in the new habitat adjust the size of their eggs to develop and hatch under new climatic conditions. It may also be advantageous in a gradually changing climate because the response occurs within generations, thus the effect is faster than evolution by natural selection. We are not aware of any other experiment testing the effect of embryonic incubation temperature on relative egg or ovarian mass, although it is known that embryonic temperature can affect characters such as sex, larval size, aggressiveness, cognition and thermal preference in reptiles (e.g. Rhen \& Crews 1999, Amiel et al. 2014). Thus, this mechanism may have much wider relevance than in salmonid fish.

Embryonic conditions did not affect female fecundity, contrary to expectations based on results from studies of latitudinal variation in this trait (Fleming \& Gross 1990, Jonsson \& Jonsson 1999). The lack of an effect may suggest that the number of oocytes produced by a female is genetically determined. Our experimental salmon had no migratory costs (cf. Crossin et al. 2004), and they were fed to satiation. This reduced the likelihood that oocytes were resorbed or lost (atresia), which may occur in latitudinal gradient studies where feeding opportunities may vary. However, growth in our study fish was no faster than that observed in wild conspecifics from the population of origin (Jonsson et al. 2003).

Large egg size should give juveniles fitness benefits when growing up in a harsh environment (whereas under benign conditions, egg size should be less important). In apparent contrast to our results, some studies on insects and fish have shown that females kept at low temperature produce larger eggs than conspecifics held in a warmer climate (Fischer et al. 2003, Bownds et al. 2010). However, salmonids are oxygen-demanding cold-water species, and warm water for eggs and young may be a less benign environment than the ambient river water. Thus, whether large or small eggs are produced in a warmer climate may depend on both the species and the environment. In an adaptive framework, eggs should be large or small depending on which size maximizes offspring survival and growth (Marshall \& Uller 2007). The important message here is that thermal climate during embryogenesis influenced the size of the eggs produced when the organisms reached adulthood.

Egg and ovarian mass increased with condition factor. It is known that condition factor is highly correlated with somatic fat and energy density of organ- isms, as found for the present study population (Jonsson \& Jonsson 2003), and large energy reserves may be a mechanism whereby females are able to produce large eggs without reducing fecundity (Pollux \& Reznick 2011). It is also known that egg size is influenced by energy costs during migration. Crossin et al. (2004) reported that egg size was reduced in sockeye populations performing particularly energydemanding migrations, and Braun et al. (2013) reported that in years of energetically demanding migration conditions, female sockeye salmon produced smaller eggs for their size than in years when conditions were more benign.

Jonsson et al. (1996) reported that Atlantic salmon egg size changes with juvenile growth rate, and similar relationships have been reported for some other salmonids (Morita et al. 1999, Tamate \& Maekawa 2000), but not for brown trout Salmo trutta (Jonsson \& Jonsson 1999) or some Pacific salmonids Oncorhynchus spp. (Quinn et al. 2004, 2011). Our results indicate that it may not be early growth per se, but elevated incubation temperature that increased juvenile growth (Finstad \& Jonsson 2012), which is associated with a larger egg size. In the present study, we found no effect of juvenile growth on egg size when the effect of thermal embryonic conditions and adult size were controlled for.

The size of the testes was largest in the warmwater incubated group and smallest in the coldwater and mixed groups, and there was a significant negative effect of fast juvenile growth. We know of no other study that has tested this. The negative correlation between juvenile growth and the mass of the testes suggests that there may be a developmental trade-off between somatic and gonadal allocation (Lee et al. 2011). When juvenile growth was high, the subsequent allocation to gonad mass decreased.

The large testes in males that experienced warm embryonic temperatures may be a developmental adaptation to breeding under warm conditions. The thermal conditions during embryogenesis may provide the organism with information about anticipated environmental breeding conditions. Experiments with sea urchin Heliocidaris tuberculata sperm showed that longevity of spermatozoa decreases with increasing water temperature (Binet \& Doyle 2013), and the same may hold for other organisms. Thus, a larger number of sperm cells, which travel in the water for external fertilization of the eggs, may compensate for an expected shorter activity period in warmer water.

Our study revealed no effect of the embryonic thermal environment on age at maturity. It is well estab- 
lished for a number of freshwater species, including salmonids, that both fast initial growth and high lipid density of the soma reduce age at maturity (Jonsson et al. 2013). Age at maturity differed between the sexes, and this appears to be an inherited sex-linked difference because environment, growth rate, size and condition factor were similar between the sexes, reducing the probability of environmentally induced effects.

The expression of fitness-related traits often exhibits clinal variation along latitudinal gradients, although the mechanisms allowing the variations remain obscure and have been ascribed to both phenotypic plasticity and genetic adaptation and combinations thereof (Sgrò \& Blows 2004, Lardies \& Bosinovic 2008, Fischer \& Karl 2010, Bentz et al. 2011). In our experiment, genetic adaptation appears unlikely, as the observed changes occurred within 1 generation, and we do not think that the small difference in mortality ( $8 \%$ ) between the 2 egg incubation temperatures in the study tanks can have caused the observed changes in life-history traits. Adaptive phenotypic plasticity may, however, involve modification of the epigenotype without change of the genomic structure of the organism, which may cause the neural, hormonal and/or enzymatic changes needed (Crews 2010, Nelson \& Monteggia 2011). Epigenetic effects have been shown to be involved in the differentiation of cell lines and trigger altered gene expression (Jablonka \& Raz 2009), and they can be induced by environmental temperature and contribute to adaptations to novel environments and be a source of phenotypic variation in ecological traits of fishes (Morán \& PérezFigueroa 2011, Jonsson \& Jonsson 2014) and other vertebrates (Frésard et al. 2013, Burton \& Metcalfe 2014, Varriale 2014).

The present developmental plasticity with effects on adults incubated in warmer water during embryogenesis appears to be an anticipatory response to offspring growth conditions, whereby relatively large egg size may prepare the next generation of offspring for a warm environment. Documentation of such effects may be most helpful in predicting changes in fitness-related traits as a consequence of global warming, and should be taken into account when considering growth and life-history changes observed across thermal gradients. It should also be helpful for the understanding of long-term repercussions of natal habitat variation on population dynamics, and a basis for epigenetic studies on the functional basis for adaptive plasticity in life-history traits.
Acknowledgements. We are grateful to the manager Knut Bergesen and the staff of the NINA Research Station at Ims, Norway, for rearing the fish from eggs to adults over a period of $3 \mathrm{yr}$, to Tonje Aronsen for help during sampling, and to Larry Greenberg, Karlstad University, Sweden, and 3 anonymous referees for critically reading and commenting on drafts of the manuscript. The funding that supported this work was from the Norwegian Research Council's programme Norklima (contract no 225014/E10) and the strategic grant 'Direct and indirect climate forcing of ecological processes: integrated scenarios across freshwater and terrestrial ecosystems' of the Norwegian Institute for Nature Research. The research was approved by the Norwegian Animal Research Authority (NARA).

\section{LITERATURE CITED}

Amiel JJ, Lindström T, Shine R (2014) Egg incubation effects generate positive correlations between size, speed and learning ability in young lizards. Anim Cogn 17:337-347

Atkinson D, Sibly RM (1997) Why are organisms usually bigger in colder environments? Making sense of a life history puzzle. Trends Ecol Evol 12:235-239

Beacham TD, Murray CB (1985) Effect of female size, egg size and water temperature on developmental biology of chum salmon (Oncorhynchus keta) from the Nitinat River, British Columbia. Can J Fish Aquat Sci 42: 1855-1865

Bentz BJ, Bracewell RR, Mock KE, Pfrender ME (2011) Genetic architecture and phenotypic plasticity of thermally-regulated traits in an eruptive species, Dendroctonus ponderosae. Evol Ecol 25:1269-1288

Binet MT, Doyle CJ (2013) Effect of near-future seawater temperature rises on sea urchin sperm longevity. Mar Freshw Res 64:1-9

> Blankenhorn WU, Hellriegel B (2002) Against Bergmann's rule: fly sperm size increases with temperature. Ecol Lett 5:7-10

Bownds C, Wilson R, Marshall DJ (2010) Why do colder mothers produce larger eggs? An optimality approach. J Exp Biol 213:3796-3801

> Braña F, Ji X (2000) Influence of incubation temperature on morphology, locomotor performance, and early growth of hatchling wall lizards (Podarcis muralis). J Exp Zool 286: 422-433

Braun DC, Patterson DA, Reynolds JD (2013) Maternal and environmental influences on egg size and juvenile lifehistory traits in Pacific salmon. Ecol Evol 3:1727-1740

Brockelman WY (1975) Competition, the fitness of offspring, and optimal cluch size. Am Nat 109:677-699

Burton T, Metcalfe NB (2014) Can environmental conditions experienced in early life influence future generations? Proc R Soc Lond B Biol Sci 281:20140311

> Crews D (2010) Epigenetics, brain, behavior, and the environment. Hormones 9:41-50

Crossin G, Hinch S, Farrell A, Higgs D, Lotto A, Oakes J, Healey M (2004) Energetics and morphology of sockeye salmon: effects of upriver migratory distance and elevation. J Fish Biol 65:788-810

> Descamps S, Boutin S, Berteaux D, McAdam AG, Gaillard JM (2008) Cohort effects in red squirrels: the influence of density, food abundance and temperature on future survival and reproductive success. J Anim Ecol 77:305-314 > Einum S, Fleming IA (2002) Does within-population varia- 
tion in fish egg size reflect maternal influences on optimal values? Am Nat 160:756-765

> Einum S, Hendry AP, Fleming IA (2002) Egg-size evolution in aquatic environments: Does oxygen availability constrain size? Proc R Soc Lond B Biol Sci 269:2325-2330

Engen-Skaugen T, Haugen JE, Tveito OE (2007) Temperature scenarios for Norway: from regional to local scale. Clim Dyn 29:441-453

Ewert MA, Nelson CE (1991) Sex determination in turtles: diverse patterns and some possible adaptive values. Copeia 1991:50-69

Finstad AG, Jonsson B (2012) Effect of incubation temperature on growth performance in Atlantic salmon. Mar Ecol Prog Ser 454:75-82

> Fischer K, Karl I (2010) Exploring plastic and genetic response to temperature variation using copper butterflies. Clim Res 43:17-30

- Fischer K, Brakefield PM, Zwaan BJ (2003) Plasticity in butterfly egg size: why larger offspring at lower temperatures? Ecology 84:3138-3147

Fleming IA, Gross MR (1990) Latitudinal clines: a trade-off between egg number and size in Pacific salmon. Ecology 71:1-11

Forster J, Hirst AG, Atkinson D (2012) Warming-induced reductions in body size are greater in aquatic than terrestrial species. Proc Natl Acad Sci USA 109: 19310-19314

- Frésard L, Morisson M, Brun JM, Collin A, Pain B, Minvielle F, Pitel F (2013) Epigenetics and phenotypic variability: some interesting insights from birds. Genet Sel Evol 45: 16

Gilbert SF, Epel D (2008) Ecological developmental biology. Sinauer Associates, Sunderland, MA

Hamor T, Garside ET (1977) Size relations and yolk utilization in embryonated ova and alevins of Atlantic salmon, Salmo salar L., in various combinations of temperature and dissolved oxygen. Can J Zool 55:1892-1898

Humpesch UH (1985) Inter- and intra-specific variation in hatching success and embryonic development of five species of salmonids and Thymallus thymallus. Arch Hydrobiol 104:129-144

IPCC (Intergovernmental Panel on Climate Change) (2013) Fifth Assessment Report. IPCC Secretariat, Geneva

Jablonka E, Raz G (2009) Transgenerational epigenetic inheritance: prevalence, mechanisms, and implications for the study of heredity and evolution. Q Rev Biol 84: 131-176

> Johnson JB, Omland KS (2004) Model selection in ecology and evolution. Trends Ecol Evol 19:101-108

Jonsson B, Jonsson N (2011) Ecology of Atlantic salmon and brown trout: habitat as a template for life histories. Fish and Fisheries Series, Book 33. Springer, Dordrecht

> Jonsson B, Jonsson N (2014) Early environment influences later performances in fishes. J Fish Biol 85:151-188

> Jonsson B, Jonsson N, Finstad AG (2013) Effects of temperature and food quality on age at maturity of ectotherms: an experimental test of Atlantic salmon. J Anim Ecol 82: 201-210

> Jonsson N, Jonsson B (1999) Trade-off between egg size and numbers in brown trout. J Fish Biol 55:767-783

> Jonsson N, Jonsson B (2003) Energy density and content of Atlantic salmon: variation among developmental stages and types of spawners. Can J Fish Aquat Sci 60:506-516

Jonsson N, Jonsson B, Fleming IA (1996) Does early growth rate cause a phenotypically plastic response in egg pro- duction of Atlantic salmon? Funct Ecol 10:89-96

> Jonsson N, Jonsson B, Hansen LP (2003) Marine survival and growth of sea ranched and wild Atlantic salmon. J Appl Ecol 40:900-911

> Jonsson N, Jonsson B, Hansen LP (2005) Does climate during embryonic development influence parr growth and age of seaward migration in Atlantic salmon (Salmo salar)? Can J Fish Aquat Sci 62:2502-2508

Kamler E (1992) Early life history of fishes: an energetic approach. Chapman \& Hall, London

Lack D (1947) The significance of clutch size. Ibis 89: 302-352

Lardies MA, Bosinovic F (2008) Genetic variation for plasticity in physiological and life-history traits among populations of an invasive species, the terrestrial isopod Porcellio laevis. Evol Ecol Res 10:747-762

> Lee WS, Metcalfe NB, Monaghen P, Mangel M (2011) Dynamic-state-dependent models of the trade-off between growth, damage, and reproduction. Am Nat 178: 774-786

Marshall DJ, Uller T (2007) When is a maternal effect adaptive? Oikos 116:1957-1963

> Martin TE (2008) Egg size variation among tropical and temperate songbirds: an embryonic temperature hypothesis. Proc Natl Acad Sci USA 105:9268-9271

> Morán P, Pérez-Figueroa A (2011) Methylation changes associated with early maturation stages in the Atlantic salmon. BMC Genet 12:86

Morita K, Yamamoto S, Takashima Y, Matsuishi T, Kanno Y, Nishimura K (1999) Effect of maternal growth history on egg number and size in wild white-spotted char (Salvelinus leucomaenis). Can J Fish Aquat Sci 56:1585-1589

> Murray CB, McPhail JD (1988) Effect of incubation temperature on the development of five Pacific salmon (Oncorhynchus) embryos and alevins. Can J Zool 66:266-273

Nelson ED, Monteggia LM (2011) Epigenetics in the mature mammalian brain: effects on behavior and synaptic transmission. Neurobiol Learn Mem 96:53-60

Ospina-Álvarez N, Piferrer F (2008) Temperature-dependent sex determination in fish revisited: prevalence, a single sex ratio response pattern, and possible effects of climate change. PLoS ONE 3:e2837

> Pollux BJA, Reznick DN (2011) Matrotrophy limits a female's ability to adaptively adjust offspring size and fecundity in fluctuating environments. Funct Ecol 25: $747-756$

> Potter KA, Davidowitz G, Woods HA (2011) Cross-stage consequences of egg temperature in the insect Manduca sexta. Funct Ecol 25:548-556

Quinn TP, Vøllestad LA, Peterson J, Gallucci V (2004) Influences of fresh water and marine growth on the egg size-egg number tradeoff in coho and Chinook salmon. Trans Am Fish Soc 133:55-65

Quinn TP, Seamons TR, Vøllestad LA, Duffy E (2011) Effects of growth and reproductive history on the egg sizefecundity trade-off in steelhead. Trans Am Fish Soc 140: 45-51

R Development Core Team (2009) R: a language and environment for statistical computing. $\mathrm{R}$ Foundation for Statistical Computing, Vienna. www.r-project.org

Rhen T, Crews D (1999) Embryonic temperature and gonadal sex organize male-typical sexual and aggressive behavior in a lizard with temperature-dependent sex determination. Endocrinology 140:4501-4508

Sgrò CM, Blows MW (2004) The genetic covariance among 
clinal environments after adaptation to an environmental gradient in Drosophila serrata. Genetics 167:1281-1291

Smith CC, Fretwell SD (1974) The optimal balance between size and number of offspring. Am Nat 108:499-506

Stillwell RC, Fox CW (2009) Geographic variation in body size, sexual size dimorphism and fitness components of seed beetle: local adaptation versus phenotypic plasticity. Oikos 118:703-712

Svärdson G (1949) Natural selection and egg number in fish. Rep Inst Freshw Res Drottningholm 29:115-122

Tamate T, Maekawa K (2000) Interpopulation variation in reproductive traits of female masu salmon, Oncorhynchus masou. Oikos 90:209-218

Editorial responsibility: Stylianos Somarakis, Heraklion, Greece
Tåning AV (1952) Experimental study of meristic characters in fishes. Biol Rev Camb Philos Soc 27:169-193

Varriale A (2014) DNA methylation, epigenetics and evolution in vertebrates: facts and challenges. Int J Evol Biol 2014:475981

Warner DA, Jorgensen CF, Janzen FJ (2010) Maternal and abiotic effects on egg mortality and hatchling size of turtles: temporal variation in selection over seven years. Funct Ecol 24:857-866

> Weber SB, Broderick AC, Groothuis TGG, Ellick JE, Godley BJ, Blount JD (2012) Fine-scale thermal adaptation in a green turtle nesting population. Proc R Soc Lond B Biol Sci 279:1077-1084

Submitted: April 16, 2014; Accepted: August 18, 2014

Proofs received from author(s): November 10, 2014 